\title{
Comparative Analysis of Modified Isolated Resonant Converters for Photovoltaic Application using Bidirectional Switch
}

\author{
N.Raja \\ PG Scholar \\ Department of Electrical and Electronics \\ Engineering, Mailam Engineering College \\ Mailam India
}

\author{
G.Irusapparajan \\ Professor \\ Department of Electrical and Electronics \\ Engineering, Mailam Engineering College \\ Mailam, India
}

\begin{abstract}
This paper represents a comparative study of isolated resonant topologies for photovoltaic application such as half bridge, full bridge and push pull topology. The performance of these topologies is analyzed with the help of Pulse Width Modulation (PWM) technique. The stressful behavior of the switches is reduced by soft switching technique. So, the primary side switches utilize zero voltage switching (ZVS) and output diodes utilize zero current switching (ZCS). A bidirectional switch is used at the high voltage side to provide voltage regulation over fixed frequency PWM control. Simulation results are performed by using a MATLABSIMULINK.
\end{abstract}

\section{Keywords}

LLC, ZVS, ZCS, MIC, PV, PWM

\section{INTRODUCTION}

Photovoltaic (PV) energy is the fastest growing renewable energy source. Its non-pollutant, direct power conversion characteristics make the entire system more competitive than traditional energy sources. The power conditioning system (PCS) required for the PV application must be efficient and less in cost. There are plenty of isolated topologies available. Among them, half bridge, full bridge and push pull are prominent topologies. These topologies are simple in construction and more economical. Topologies are modified, so that they can have efficient power tracking from the PV panel. The performance of these topologies is characterized in graphical representation. The topology is designed so as to have high voltage gain, for that a bidirectional switch is provided at the high voltage side of the transformer. The bidirectional switch is formed by connecting two MOSFETs drain terminals together. Single driver unit is required to operate the switch. The switching frequency of the bidirectional switch will be twice that of the resonant frequency.

\section{RELATED WORKS}

This section deals with the related works done for the proposed system. Thomas LaBella et al., [1] proposed a bidirectional switch based on isolated resonant converter for PV application. The regulation of voltage can be combined by the application through a fixed-frequency PWM control along with LLC converters by adding a bidirectional switch at secondary side of the isolation transformer. D. Cao et al., proposed a half bridge micro-inverter for single phase grid connected PV system with continuous input current and reduced transformer turns ratio [2]. A transformer less single phase topology with maximum power point tracking (MPPT) is introduced by D. Meneses et al., [3]. Z. Liang et al., [4] implemented a dual mode resonant converter topology for parallel connected dc module integrated converter (MIC). An LLC converter with substantial resonant inductance for wide input voltage regulation is established by R. Beiranvand et al., [5]. T.-H. Hsia et al., [6] proposed an interleaved soft switching (zero voltage and zero current switching) technique.

A forward flyback converter using dual constant on-time modulating for wide input voltage regulation is proposed by W. Yu et al., [7]. Q. Li and P. Wolfs [8] described the three different DC link configurations for module integrated topologies. The wide output voltage range with optimized design procedure of LLC resonant converter is examined by R. Beiranvandet al., [9]. B. Gu et al., [10] established a transformer with less topology and with two split ac-coupled inductors which work separately for negative and positive half grid cycle. F. Musavi et al., [11] developed an LLC resonant converter for battery charging applications with wide output voltage range that eliminates both low and high frequency current ripples. An improved LLC converter utilizing two series transformers for changing the magnetizing inductance to reduce magnetizing current is developed by $\mathrm{H}$. $\mathrm{Hu}$ et al., [12]. The leakage inductance energy recovery for the isolation transformer of interleaved flyback converter is modelled by G. Jun-yin et al., [13]. Fariborz Musavi et al., [14] have addressed the limitations of LLC converter, implemented the current mode control and optimization of burst mode operation for current regulation. Y. Chen et al., [15] proposed a design method of wide output range constant current LLC resonant converter. B.-G. Chung and K.-H. Yoon et al., [16] developed a converter with two resonant tank circuits and auxiliary switches to get the high voltage gain characteristics with wide input voltage and load. A fixed frequency zero voltage switching three-level DC/DC resonant converter with phase-shift control between the primary and secondary sides of the transformer is designed by F. Canales and P. Barbosa et al., [17] to make the converter work at a fixed switching frequency. T. LaBella et al., [18] established an active-clamp fly back converter using Gallium Nitride based MOSFETs for reducing the losses that occur during dead time. M. M. Jovanovic et al., [19] proposed a high-frequency quasiresonant buck converter using graphical state-plane technique. B. Yang et al., [20] developed a LLC resonant converter for front end DC/DC conversion.

\section{PROPOSED WORK}

The PCS used for the PV application must convert low voltage into high voltage. In order to improve the step upping process, the proposed work deals with the modified isolated resonant topologies for $\mathrm{PV}$ application. Isolated resonant topologies are power converters which give necessary isolation between the source and load. The power tracking from the PV module is done efficiently by the isolated 
converters and it also boosts low input voltage to high output voltage according to the requirement. The conversion is accomplished by PWM technique. This paper mainly focuses on the comparative study of three isolated topologies (half full and push pull)

\subsection{Half Bridge Topology}

Figure 1 shows the arrangement of half bridge topology and it has two switches at the front end converter. Unlike the full bridge converter, it has two capacitors at low voltage side, so the voltage across the primary winding always is half of the input voltage $\mathrm{V}_{\mathrm{S}} / 2$.

There are four modes of operations are possible with the half bridge topology:

Mode 1: In this mode $\mathrm{S} 1$ is turned $\mathrm{ON}$ and $\mathrm{S} 2$ is turned OFF. The transformer gets current through $\mathrm{S} 1$ and $\mathrm{C} 2$, now the bidirectional switch S3 is turned ON. Hence it shorts the high voltage side of the transformer. During this time leakage inductance $\mathrm{Lr}$ will store the energy.

Mode 2: During mode 2, the switch S3 will be switched OFF. Then, the stored energy of the Lr discharges to the load.

Mode 3: In mode 2 the switch S2, is turned ON and S1 is switched OFF. Transformer gets current through S2 and C1.

Mode 4: The operation of mode 2 is repeated in this mode.

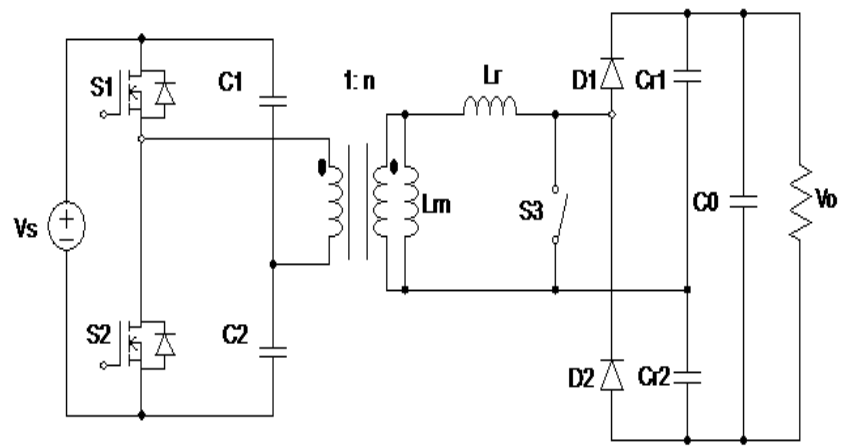

Fig 1: Half bridge topology

During the mode 1 , the primary voltage will be $\mathrm{V}_{\mathrm{S}} / 2$. So the primary current starts to build up. The voltage across the primary winding is given by

$$
V_{s e}=\frac{n_{s}}{n_{p}} * \frac{v_{s}}{2}
$$

Where $-n_{s}$ and $n_{p}$ are the secondary and primary turns of the transformer. Vs is the source voltage. During the mode 2 of the half bridge network the primary voltage will be $-\mathrm{V}_{\mathrm{S}} / 2$. The output voltage of the half bridge topology will be,

$$
V_{0}=\frac{n_{s}}{n_{p}} v_{s} k
$$

$k$ is the constant. The output voltage of the half bridge topology can be found from the time integral of the inductor.

\subsection{Full Bridge Topology}

Figure 2 shows the arrangement of full bridge topology, it contains four switches at the front end converter. For this full bridge topology there are different modes of operations are possible:

Mode 1: In this mode the switches S1 and S4 are switched ON. It makes current flow through the transformer. So the bidirectional switch S5 is turned ON, hence it shorts the secondary of the transformer.

Mode 2: In this mode S5 will be switched OFF. Hence current flow takes place through the load.

Mode 3: In this mode, the switches S2 and S3 are turned ON, now the switches S1 and S4 will be switched OFF. During this time, S5 shorts the secondary of the transformer.

Mode 4: In mode 4, the bidirectional switch will be switched OFF. Hence the current flow takes place through the load.

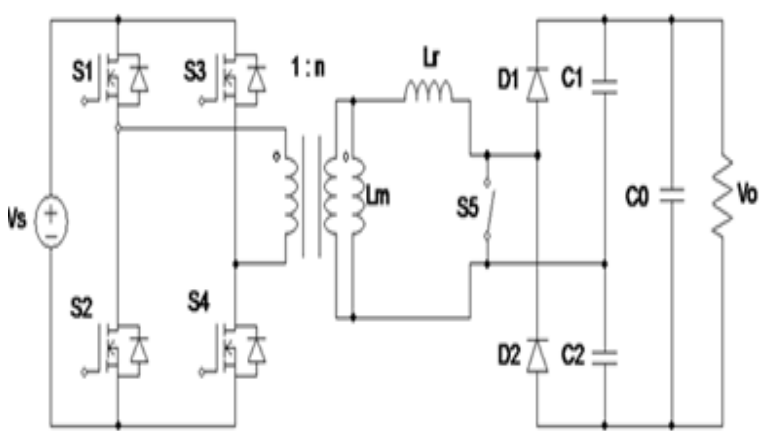

Fig 2: Full bridge topology

During mode 1 , the voltage across secondary winding will be,

$$
V_{S e}=\frac{n_{s}}{n_{p}} v_{S}
$$

Now the inductor current will increase linearly. Output voltage can be written as,

$$
V_{0}=\frac{n_{s}}{n_{p}} 2 v_{s} k
$$

Where $-n_{s}$ and $n_{p}$ is the secondary and primary turns of the transformer.

\subsection{Push Pull Topology}

Figure 3 shows the arrangement of push pull topology. It has two switches at the front end converter. The switches and capacitors required for this topology will be less when compared with other topologies (half and full). When S2 is turned $\mathrm{ON}, \mathrm{Vs}$ appears at one half of the primary voltage. During this time $\mathrm{S} 2$ will be in OFF condition.

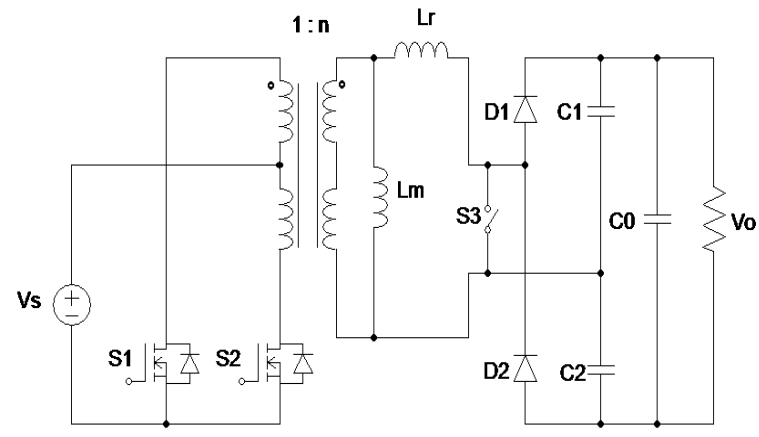

Fig 3: Push pull topology

When $\mathrm{S} 1$ is in turned $\mathrm{ON},-\mathrm{V}_{\mathrm{S}}$ appears at the other half of the primary winding. Hence the output voltage can be written as,

$$
V_{0}=\frac{n_{s}}{n_{p}} v_{s}
$$


Where $-n_{s}$ and $n_{p}$ are the secondary and primary turns of the transformer. The average current through the transformer should ideally be zero.

\section{A BIDIRECTIONAL SWITCH}

Unlike the conventional topologies, a bidirectional switch is implemented at the high voltage side of the isolated transformer. The advantage of using bidirectional switch at the secondary side is to enhance the storage capability of the inductor $\mathrm{L}_{\mathrm{r}}$ the arrangement of bidirectional switch is shown in Figure 4.

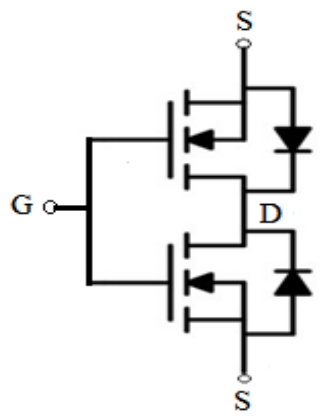

Fig 4: Bidirectional switch

A bidirectional switch is formed by connecting two MOSFET's drain terminal. A common gate pulse drive is enough for this type of arrangement. The switching frequencies of these topologies are $130 \mathrm{KHz}$ but the switching frequency of the bidirectional switch is reduced by half. When this switch is turned $\mathrm{ON}$, it shorts the secondary of the isolated transformer then the inductor $\mathrm{L}_{\mathrm{r}}$ is allowed to charge fully. When it is switched OFF then the stored energy is discharged to the load through the output diodes.

\section{RESONANT TANK DESIGN AND TURNS RATIO}

The resonant inductance $\mathrm{Lr}$ should be large enough. The selection of which will totally vary from the selection of LLC converters. In LLC converter, $\mathrm{Lr}$ is depends on the ratio between leakage and magnetizing inductance. By this ratio, a proper conversion can be obtained. But in the proposed system, it is independent of conversion ratio because it acts as a PWM boost inductor.

The input voltage of front end converter will vary from (10V$60 \mathrm{~V}$ ), so the proposed converter is capable of wide input voltage regulation. The low input voltage can be stepped up with the help turns ratio $(1: n)$ of the isolation transformer.

$$
n=\frac{V_{0(\text { output voltage })}}{2 V_{(\text {input voltage }) \text { nom }}}
$$

The transformer's turns ratio should be selected at the resonant frequency where the gain is unity.

\section{SOFT SWITCHING}

There are many control techniques which are affected by conduction losses in the switches and EMI (Electromagnetic Interference). These drawbacks are rectified by soft switching technique. It includes both ZVS and ZCS. For better understanding, let's consider MOSFET. MOSFET operating at high frequency has switching losses due to non-dissipation of charge that is stored in the internal capacitance of the MOSFET during its turn ON period. So the switch must be turned $\mathrm{ON}$ under zero voltage switching condition.

\subsection{Zero Voltage and Zero Current Switching}

For zero voltage switching of MOSFET operating under higher frequency, a capacitor must be connected in parallel to the MOSFET as shown in Figure 5.

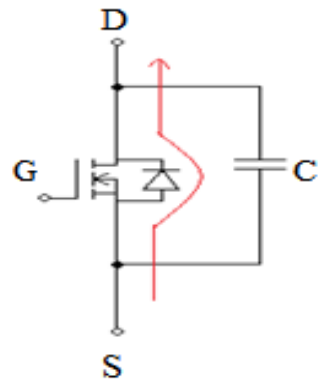

Fig 5: Zero voltage switching

The MOSFET will conduct only if it gets the gate pulse. Before applying the gate voltage to turn ON the MOSFET, the switch voltage brought to zero and the anti-parallel diode is conducting. So it results, lossless turn $\mathrm{ON}$ of a switch. In the case of zero current switching, the diodes at the high voltage side are turned ON/OFF at zero current.

\section{SIMULATION RESULTS}

The simulation results of the proposed topologies represents the output voltage and output current of the isolated resonant topologies

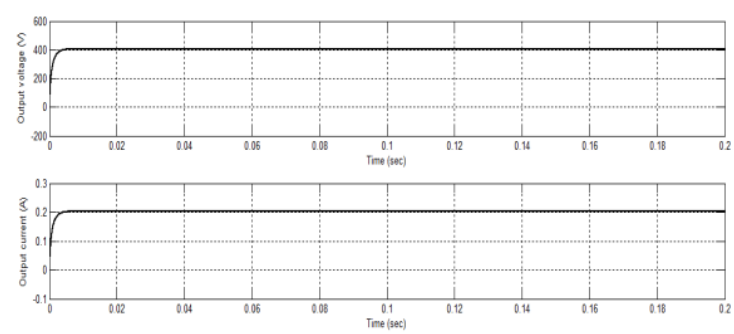

a) Output voltage and current of full bridge topology
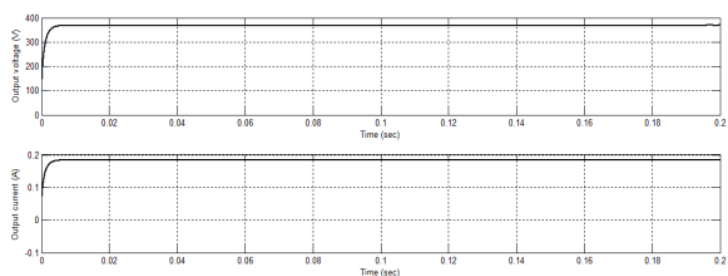

b) Output voltage and current of half bridge topology

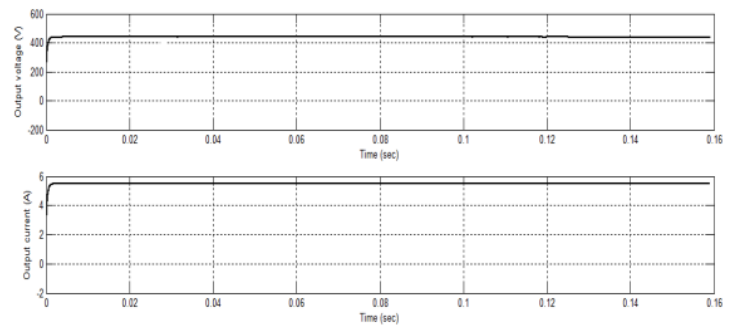

c) Output voltage and current of push pull topology

Fig 6: The Output voltage and Current wave form of proposed topologies for input voltage $100 \mathrm{~V}$. 
Figure 6 shows the output voltage and current of the isolated resonant topologies (half full and push pull). Here the input voltage of these topologies has taken as $100 \mathrm{~V}$. The input voltage and corresponding output voltage for these topologies are shown in the Table 1 .

\section{Table 1.Comparative analysis of isolated resonant} topologies

\begin{tabular}{|c|c|c|c|}
\hline $\begin{array}{c}\text { Input } \\
\text { voltage } \\
\text { to the } \\
\text { resonant } \\
\text { topology } \\
\text { (V) }\end{array}$ & $\begin{array}{c}\text { Output } \\
\text { voltage } \\
\text { of half } \\
\text { bridge } \\
\text { topology } \\
\text { (V) }\end{array}$ & $\begin{array}{c}\text { Output } \\
\text { voltage } \\
\text { of full } \\
\text { bridge } \\
\text { topology } \\
(\mathrm{V})\end{array}$ & $\begin{array}{c}\text { Output } \\
\text { voltage } \\
\text { of push } \\
\text { pull } \\
\text { topology } \\
(\mathrm{V})\end{array}$ \\
\hline 20 & 76.66 & 80.22 & 88.09 \\
\hline 40 & 154.6 & 161.6 & 176.2 \\
\hline 60 & 232.7 & 243 & 264.5 \\
\hline 80 & 319 & 324 & 352.6 \\
\hline 100 & 387.6 & 405.4 & 441.4 \\
\hline
\end{tabular}

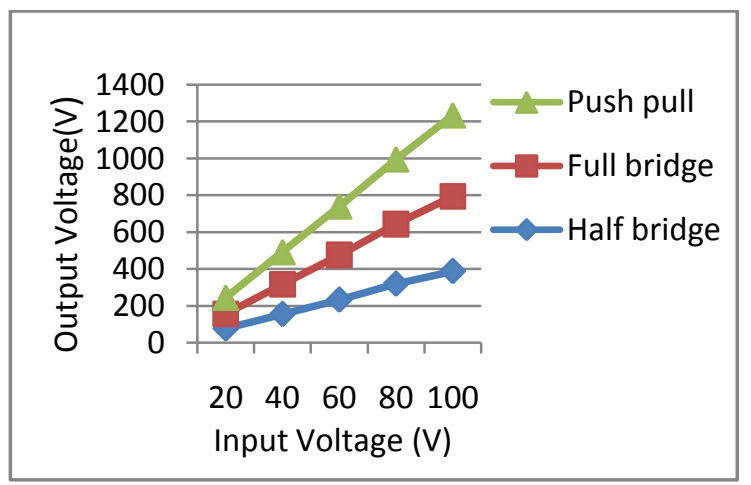

Fig 7: Performance comparison of resonant topologies

The Figure 7 shows the graphical realization of the proposed converters for PV application to form this analysis. It is clearly identified that the output of push pull topology is high when compared with the other two topologies.

\section{CONCLUSION}

In this paper, the comparative study of the isolated resonant topologies is proposed. Based on the performance, the Push pull topology has high voltage gain than the remaining topologies. The requirement of switches and elements will be low when compared with the other two (half bridge and full bridge) topologies. Hence, it results low switching losses, low cost and higher efficiency. The performance of half bridge converter is low when compared with full and push pull topology. So the desired features can be obtained through push pull arrangement for tracking power from the PV module. Hence the push pull topology can be used widely in PV applications.

\section{REFERENCES}

[1] Thomas LaBella, Wensong Yu, Jih-Sheng (Jason) Lai, Fellow, Matthew Senesky, and David Anderson, "A Bidirectional-Switch-Based Wide-Input Range HighEfficiency Isolated Resonant Converter for Photovoltaic Applications," IEEE Tans. Power Electron, vol. 29, no.7, pp. 3473- 3484, July 2014.
[2] D. Cao, S. Jiang, F. Z. Peng, andY.Li, "Lowcost transformer isolated boost half-bridge micro inverter for single-phase grid connected photovoltaic system," IEEE Appl. Power Electron. Conf.Expo. (APEC), pp. 7178.2012.

[3] D. Meneses, F. Blaabjerg, O. Garcia, and J. A. Cobos, "Review and comparison of step-up transformerless topologies for photovoltaic AC-module application," IEEE Trans. Power Electron., vol. 28, no. 6, pp. 2649-2663, Jun. 2013.

[4] Z. Liang, R. Guo, J. Li, and A. Q. Huang, "A highefficiency PV moduleintegrated DC/DC converter for PV energy harvest in FREEDM systems," IEEE Trans. Power Electron., vol. 26, no. 3, pp. 897-909, Mar. 2011.

[5] R. Beiranvand, B. Rashidian,M. R. Zolghadri, and S. M. H. Alavi, "Using LLC resonant converter for designing wide-range voltage source," IEEETrans. Ind. Electron. vol. 58, no. 5, pp. 1746-1756, May 2011.

[6] T.-H. Hsia, H.-Y.Tsai, D. Chen, M. Lee, and C.-S Huang, "Interleaved active-clamping converter with ZVS/ZCS features," IEEE Trans. PowerElectron., vol. 26, no. 1, pp. 29-37, Jan. 2011.

[7] W. Yu, B. York, and J.-S.Lai, "Inductorless forwardflybacksoft switching converter with dual constant ontime modulation for photovoltaic applications," IEEE Energy Convers. Cong. Expo.(ECCE), pp. 35493555,2012 .

[8] Q. Li and P.Wolfs, "A review of the single phase photovoltaic module integrated converter topologies with three different DC link configurations," IEEE Trans. Power Electron., vol. 23, no. 3, pp. 1320-1333, May 2008.

[9] R. Beiranvand, B. Rashidian, M. R. Zolghadri, and S. M. H. Alavi, "A design procedure for optimizing the LLC resonant converter as a wide output range voltage source," IEEE Trans. Power Electron., vol. 27, no. 8, pp. 3749-3763, 2012.

[10] B. Gu, J. Dominic, J.-S. Lai, C.-L. Chen, T. LaBella, and B. Chen, "High reliability and efficiency single-phase transformerless inverter for grid connected photovoltaic systems," IEEE Trans. Power Electron., vol. 28, no. 5, pp. 2235-2245, May 2013.

[11] F. Musavi,M. Craciun, D. S. Gautam,W. Eberle, andW. G. Dunford, "An LLC resonant DC-DC converter for wide output voltage range battery charging applications," IEEE Trans. Power Electron., vol. PP, no. 99, p. 1-1, Dec. 2013.

[12] H. Hu, X. Fang, F. Chen, Z. J. Shen, and I. Batarseh, “A modified highefficiency LLC converter with two transformers for wide input-voltage range applications," IEEE Trans. Power Electron., vol. 28, no. 4, pp. 19461960, Apr. 2013.

[13] G. Jun-yin,W. Hong-fei, C. Guo-cheng, and X. Yan, "Research on photovoltaic grid connected inverter based on soft-switching interleaved flyback converter," IEEE Conf. Ind. Electron. Appl. (ICIEA), pp. 1209-1214,2010.

[14] Fariborz Musavi, Marian Craciun, Deepak S. Gautam, and Wilson Eberle, "Control Strategies for Wide Output Voltage Range LLC Resonant DC-DC Converters in 
Battery Chargers,'IEEE Trans. On vehicular technology, vol. 63, no. 3, March 2014.

[15] Y. Chen, X. Wu, Z. Qian, and W. Zhang, "Design and optimization of a wide output voltage range LED driver based on LLC resonant topology," IEEE 8th Int. Conf. Power Electron.ECCE Asia (ICPE \&ECCE), pp. 28312837, in Proc. 2011.

[16] B.-G. Chung, K.-H.Yoon, S. Phum, E.-S.Kim, and J.-S. Won, "A novel LLC resonant converter for wide input voltage and load range," IEEE 8th Int. Conf. Power Electron. ECCE Asia (ICPE \& ECCE), pp. 2825-2830,in Proc.2011.

[17] F. Canales, P. Barbosa, and F. C. Lee, "A wide input voltage and load output variations fixed-frequency ZVS DC/DC LLC resonant converter for high-power applications," $37^{\text {th }}$ IAS Ann. Meeting. Conf.Rec. Ind. Appl. Conf., vol. 4, pp. 2306-2313,in Proc. 2002.

[18] T. LaBella, B. York, C. Hutchens, and J.-S. Lai, "Dead time optimization through loss analysis of an activeclamp flyback converter utilizing GaN devices," IEEE Energy Convers. Cong. Expo. (ECCE), pp. 3882-3889, in Proc. 2012.

[19] M. Jovanovic, K.-H. Liu, R. Oruganti, and F. C. Lee, "State-plane analysis of quasi resonant converters," IEEE Trans. Power Electron., vol. PE- 2, no. 1, pp. 36-44, Jan. 1987.

[20] B. Yang, F. C. Lee, A. J. Zhang, and G. Huang, "LLC resonant converter for front end DC/DC conversion," in Proc. 17th Annu. IEEE Appl. PowerElectron. Conf. Expo., vol. 2, pp. 1108-1112, (APEC 2002) 